\title{
Reshaping Social Identity: A Qualitative Report on Experiences in an Interracial Median Group
}

Hilary Vice and Assie Gildenhuys

A median group convened in Johannesburg, South Africa, is described as offering its members multiple opportunities to reshape their social identities and engage in a process of social learning. The group was one component of a course in group work. Group analytic theory positioned the work within a context that was characterised by transition and social trauma. A richly diverse group composition, which reflected many dimensions of the interracial macro-society, was an important aspect of the group. The group was researched using a qualitative, multi-method research design, utilising participant observation, in-depth interviews and focus groups. These different approaches gave access to the group members' subjective experiences and meaning-making strategies. The researcher's engagement with the research process and her own social reshaping emerged as an important dimension of the research. In conclusion, some thoughts on working in an interracial median group in a transformational society are offered.

Key words: interracial median group, social learning, social identity, qualitative research, multi-method research

\section{Introduction}

This article describes a median group in Johannesburg, South Africa, that is one aspect of a group analytically informed programme called Working with Groups (WwG). The median group was the focus of a year-long research project in which both the writers 
participated. ${ }^{\mathrm{i}}$ The research took place 15 years after the 1994 democratic elections that ended apartheid. The various events that are described are contextualised by this time frame.

The macro-society at the time was characterised by ongoing political, social and economic tensions exaggerated as a result of the national elections that were held that year, with violent service delivery protests and outbreaks of xenophobia being a constant feature. The global recession, as well as economic re-structuring on a national level, had placed the organisation where the project took place, in a financial crisis.

\section{The median group as a transitional space}

A median group approach, informed by the work of De Maré (1985, 1990, 1994, 2002) and De Maré, Piper and Thompson (1991) was convened as part of the WwG course. This approach was chosen owing to the applied nature of the work and the regular meetings that were possible over the six block weekends (Behr \& Hearst, 2005). The group had 31 members and 5 staff.

A median group approach is understood by the writers as operating at the juncture where the personal and the social aspects of identity overlap. Experiential exploration of this interface was possible as five small groups, spread throughout the weekend, and three median groups, held at the end of each day, were offered. In both these spaces exploration of the self as a member of multiple, interdependent networks (Rogers, 2013) became possible. As the foundation matrix interacted with the dynamic matrix in a process of reciprocal exchange (Foulkes, 1964), the group members were able to explore the historical, social, cultural and political reality of the broader social context and the effect of those influences on their lives and professional activities.

Berman (2014) describes the ability to respond flexibly to sameness and otherness as a basic requirement for healthy relationships. In the heterogeneous, racially and culturally 
mixed group described here, numerous encounters with the racial and cultural 'other' were possible that encouraged a growing awareness of similarities to, and differences from, others. This was important in the South African context as the apartheid government not only separated black and white groups, but also segregated groups according to ethnicity. The value placed on learning to dialogue with others in a group analytic median group was seen as offering a helpful response to these ruptured social relations.

Although the majority of South Africans now interact with peers from a different race and culture at school, university and in the workplace, these interactions are often defined and limited by occupational roles, making the contact formal and fairly superficial. In addition, continuing structural and demographic realities shape these engagements (Durrheim, Mtose, \& Brown, 2011). Consequently the historical positioning of the different racial groups, as well as current realities, magnify the feelings of hostility and suspicion when groups interrelate.

Median groups broaden the unconscious processes operating in the group and intrusions of unprocessed traumatic experience are likely to occur in groups operating in transformational settings as Becker, Beech and Spiro (2013), Mojovic (2007), Rohr (2013) and Von Sommaruga Howard (2012) have shown. The staff team convening this median group were informed regarding the social unconscious by authors such as Brown (2001), Dalal (2001), Hopper (2001, 2003b, 2011) and Weinberg (2007). In addition they were aware of the value of the group as offering an alternative paradigm to the accepted social order (De Mendelssohn, 2000). However, in this report, this feature of the group is not discussed in detail as the focus is on the experiential dimension as revealed by the members themselves. For example, the multiplicity of different voices and social positions in the group allowed a continuous re-construction of social identity. Simultaneously, the relational and communicational matrix of the group underwent ongoing transformations as the individual 
members, subgroups and the group-as-a-whole were reshaped through participation in the group.

\section{The Working with Groups [WwG] course}

The Working with Groups course was developed in response to the mental health needs in South Africa following the 1994 democratic elections. At the time of writing the WwG course is in its $11^{\text {th }}$ year. In developing the course the staff team aimed to enhance and support the work of other organisations through the personal development of the trainees. A further aim was to equip these future group practitioners to work in contexts characterised by social trauma, uncertainty and tensions in interracial relationships.

The staff team consisted of two women and three men each contributing extensive expertise from a diverse spectrum of group work. One of the authors, Gildenhuys, was a member of the staff in the year described, whilst Vice relinquished her role as a staff member to undertake the research. ${ }^{\text {ii }}$

\section{The course structure}

The programme was structured to accommodate the diversity of the group composition and the training needs of the participants. Consequently, in the year being described, four different programmes ran concurrently during each block. An Introductory programme (14 members) modelled on group analytic courses offered elsewhere, (Island, 2003; Lorentzen, 2004) could be followed by the Intermediate programme ( 8 members) which trained both professional and non-professional group workers to offer groups in a variety of applied settings. In addition, a Training group (6 members) was undergoing an intensive programme in group analytic psychotherapy. Three additional individuals, the Experiential group, joined the Training group for a therapeutic experience and were members 
of the median group. An anomaly that year was that there was only one white median group member in the first or the second year groups, with the remaining six white group members concentrated in the advanced Training group. This introduced a historical power dynamic that will be discussed below.

The course members met in small experiential groups, work discussion groups and attended lectures and theory seminars with an emphasis placed on self-development through experiential learning and reflective practice. The median group was a central component of the course and met at the end of each day. A male, black staff member was the convenor of the median group.

The multi-component course structure provided multiple opportunities for social learning as the staff team and the course members engaged with one another in different settings and in different roles. In addition, the different levels of course experience had an impact on the group culture. The Introductory members brought new material into the foundation matrix whilst the continuing group members carried the group culture as part of the dynamic matrix and provided stability for the group.

\section{The group composition}

In designing the course the staff team had been aware that group practitioners need to be mindful of their cultural assumptions to work effectively in the South African context. Consequently minimal selection criteria were applied for entry to the Introductory (first year) programme so that a diverse membership would be attracted. The end result was a group of 31 members who varied across gender, race, home language, educational background and age. Table 1 shows the composition of the group in the year described. [ ${ }^{\mathrm{iii}}$ see note on ethics] 
Table 1:

The 31 group members according to gender, race, home language, education and age

\begin{tabular}{|c|c|c|c|c|c|c|c|c|}
\hline Gender & & \multicolumn{2}{|c|}{ Race } & \multirow{2}{*}{$\begin{array}{c}\text { Home } \\
\text { Language }\end{array}$} & \multicolumn{2}{|c|}{ Education } & \multicolumn{2}{|c|}{ Age Range } \\
\hline & $\mathbf{N}$ & & $\mathbf{N}$ & & & $\mathbf{N}$ & & $\mathbf{N}$ \\
\hline \multirow{10}{*}{ Men } & \multirow{10}{*}{10} & \multirow{6}{*}{ Black } & \multirow{6}{*}{9} & $1 \mathrm{E}$ & \multirow{2}{*}{ Tertiary } & \multirow{2}{*}{2} & $20-30$ & 2 \\
\hline & & & & $2 \mathrm{~S}$ & & & $30-40$ & 5 \\
\hline & & & & $\begin{array}{l}1 \mathrm{Se} \\
1 \mathrm{U}\end{array}$ & \multirow{4}{*}{ Secondary } & \multirow{4}{*}{7} & $40-50$ & 1 \\
\hline & & & & $1 \mathrm{~V}$ & & & & \\
\hline & & & & $1 X$ & & & +50 & 1 \\
\hline & & & & $2 Z$ & & & & \\
\hline & & \multirow{4}{*}{ White } & \multirow{4}{*}{1} & \multirow{4}{*}{$1 \mathrm{E}$} & \multirow{2}{*}{ Tertiary } & \multirow{2}{*}{1} & $20-30$ & 0 \\
\hline & & & & & & & $30-40$ & 1 \\
\hline & & & & & \multirow{2}{*}{ Secondary } & \multirow{2}{*}{0} & $40-50$ & 0 \\
\hline & & & & & & & +50 & 0 \\
\hline \multirow{8}{*}{ Women } & \multirow{8}{*}{21} & \multirow{5}{*}{ Black } & \multirow{5}{*}{$\begin{array}{l}1 \\
5\end{array}$} & $1 \mathrm{E}$ & \multirow{2}{*}{ Tertiary } & \multirow{2}{*}{9} & $20-30$ & 6 \\
\hline & & & & $1 \mathrm{~S}$ & & & $30-40$ & 3 \\
\hline & & & & $5 \mathrm{U}$ & \multirow{3}{*}{ Secondary } & \multirow[b]{2}{*}{6} & $40-50$ & 3 \\
\hline & & & & $1 \mathrm{X}$ & & & +50 & 3 \\
\hline & & & & \multirow{4}{*}{$\begin{array}{l}2 \mathrm{~A} \\
4 \mathrm{E}\end{array}$} & & & $20-30$ & 0 \\
\hline & & \multirow{3}{*}{ White } & \multirow{3}{*}{6} & & Tertiary & 6 & $\frac{20-50}{30-40}$ & 4 \\
\hline & & & & & \multirow{2}{*}{ Secondary } & \multirow{2}{*}{0} & $40-50$ & 0 \\
\hline & & & & & & & +50 & 2 \\
\hline
\end{tabular}

Key: $\mathrm{A}=$ Afrikaans, $\mathrm{E}=$ English, $\mathrm{N}=$ Ndebele, $\mathrm{S}=$ Sepedi, $\mathrm{Se}=$ Sesotho, $\mathrm{Sw}=$ Swati, $\mathrm{T}=$ Tsonga, Ts= Tswana, $\mathrm{U}=$ Unspecified, $\mathrm{V}=\mathrm{Venda}, \mathrm{X}=\mathrm{Xhosa}, \mathrm{Z}=\mathrm{Zulu}$

There was a considerable age range with the youngest participant being 27 years old and the oldest 60 years old. Any black group member older than 33 years would have received his/her entire schooling under the apartheid system of education, which advantaged white students and severely disadvantaged black students, limiting their opportunities for personal advancement, well-paid employment and tertiary education. Thirty-five percent of the group were in this category.

Of the 18 group members with tertiary education, 14 were professionals in the mental health field. The remainder included a remedial teacher and three group members with degrees in anthropology, theology and business respectively. 
The 13 black participants with no post-school education included six women who were all employed as non-professional/lay counsellors in organisations which focused on family and gender issues, and the trauma of violence, rape and child abuse. The seven males included three men who worked for the local municipality/council as meter readers, another three who were involved in community development programmes, and a community activist. These 13 group members were living on extremely low incomes (below R3 000/\$250 per month) in under-resourced areas. They rented accommodation that could be one room in another person's home or an outbuilding without electricity or running water.

All the black members spoke English in addition to two, three or four African languages. None of the white group members spoke a black language to any level of proficiency. Although the communication medium of the WwG course was English, the course members were encouraged to use their own home language, with interpretation being provided by others as required. However, the use of other languages, including Afrikaans (which, with English, was an official language under apartheid) was a rare occurrence.

\section{The stance of the staff team}

The group composition and the different course strata created a median group membership that was intergenerational as well as interracial. The staff team had to hold this complex group composition structure and respond creatively to a broad range of themes communicated in many different ways. The unchartered territory characterised by social distance and lack of connection required an openness to learning and the ability to adapt responsively to the varied needs of the group members.

\section{The multi-method research design}

A multi-method, qualitative research design was created that provided different 
perspectives from which the median group experience could be investigated. This design also permitted the evolution of both the individual and group to be monitored over time.

Three sources of experiential information were used: participant observation of the median group, in-depth, individual interviews and focus groups. ${ }^{\text {iv }}$ In addition, the researcher's engagement with her experiences was a rich source of information. These various research spaces gave entry to the lived social worlds of the group members and the impact of their personal social circumstances, both current and developmental, on the relational and communicational matrix of the group. A unique opportunity for the subjective experience of the median group to be understood from the perspective of the group members themselves was thus made possible. In addition, important material that could not be shared in the median group emerged in these spaces beyond the median group boundary.

As a participant observer in the median group the researcher sat on the periphery of the group observing the group and writing a verbatim transcript. This participation created a shared frame of reference for the researcher and the group members. Based on these observations a representative selection of group members was chosen to be interviewed or to take part in a focus group.

The interviews began after the third block, after a slow start characterised by group members failing to attend at the scheduled times. The interviews highlighted the extent to which the members' social identities were shaped by their internal worlds, interacting with the constraints of the past and the current circumstances in which they found themselves. In the median group the researcher was able to observe these personal meanings being given expression as the group members responded to the themes being expressed in the group. In turn, the members' contributions shaped the communicational and relational matrix of the group.

The focus groups of 12-15 members provided an intimate setting with a structured 
protocol that encouraged a focus on the immediacy of the members' experiences. The lively interaction that developed helped the focus group members to connect with their experiences and encouraged them to discuss issues candidly. Quiet members often spoke for the first time in these groups. Material that had not been shared in the median group emerged in these groups and enhanced the researcher's understanding of the median group process.

The observation of the median group, the individual interviews and the focus groups thus enabled more of the social matrix to be shared as well as making different types of experiential information accessible (Tindall, 2006).

\section{The relational interaction: The early stages of the group}

In the discussion that follows reference is made to an 'early' stage and a 'later' stage. The 'early' stage refers to approximately the first three blocks with the 'later' stage beginning thereafter and continuing until the end of the year.

To give the reader a sense of the group in the 'early' phase a vignette from the first median group session of the year is given. The various dimensions of social identity such as race, culture, age, gender, language group, political affiliation and course level all influenced the interaction that occurred. The individual member is understood as responding to the social matrix 'in a highly individualised way based on his/her own development and characteristic defences, resonating "in the key to which he is attuned" and according to current needs and preoccupation' (Foulkes, 1990: 298).

\section{Vignette 1.}

The atmosphere had been uneasy throughout the session as the group questioned the meaning of the group and how to connect when there was no trust between them. Twenty 
minutes before the end of the session, a young, male, black group member, $B$, stood up to speak, having explained previously that he would stand to speak out of 'respect to elders present'. He spoke about the fact that 'parents are there to guide but that you can't get all you need from them'. He said he had seen a white counsellor and that he hadn't thought she could help him because she was white, but in fact she did help him. Turning to face an older, black woman, $A$, he said: 'Mama, will you please stand up?' She stood and then as $B$ continued to speak at considerable length she sat down again. The content that $B$ seemed to be trying to convey was not clear, but suggested an idea of older people having something to offer.

Nobody commented on this incident directly at first. A member of the staff team then asked if the group felt they were not safe and whether they felt they could they trust the staff? Four people responded, including $A$ who said she felt that they had been 'deliberately abandoned' by the staff. The same staff member made another supportive comment. A white female, one of two Afrikaans speaking group members, $C$, entered the conversation abruptly, sounding angry, asking why females obey males. Turning to $A$ she asked why she had obeyed the young man saying that that she wouldn't have done so. 'Is this something you do in your culture?' she asked. $A$ said she was not upset, as she knew $B$ from her small experiential group. One of the staff team likened the incident to being in a community where one does 'what one is told'. A responded, saying that maybe she had been sleepy and had 'got a wakeup' when $B$ spoke. She asked $C$ : 'Would you have stood up?' $C$ didn't answer this question but asked again, in a demanding tone, if this was 'how you do things in your culture?' This was greeted with mutters and angry looks and then suddenly the group members were speaking all at once in dyads, small subgroups and with some trying to address the whole group. $C$ seemed oblivious to the group tension but she responded to $A$ acknowledging that she might herself have stood up in some circumstances. The atmosphere was extremely hostile and tense as the convenor indicated the end of the session, with many 
members talking in agitated tones in dyads and small subgroups as they left the room. Other group members left quietly and alone.

\section{Discussion of the vignette}

The commotion that erupted in the group was in response to $C$ 's accusing tone and her use of the words 'your culture' which were taken to imply a demeaning assumption that all people of a certain (black) culture would stand up for a man regardless of the context. The black group members felt offended by this assumption and a group of them homogenised, drawing on their large group identity (Volkan, 2001) as black people and supporting $A$ with their solidarity.

The group seemed unable to speak about the memories and experiences of apartheid and the way in which that trauma was re-ignited in interactions between white and black group members, such as that between $B$ and $C$, or between different ethnic or language groups. Her comments galvanised an enactment of experiences and feelings that could not be expressed verbally at this early stage of the group's development. What became alive was the power of apartheid to construct a black person as inferior and the powerful feelings of being de-humanised, humiliated and shamed as a result.

In this session, and in subsequent sessions in the first few blocks, homogenising into subgroups based on an aspect of social identity that had been foregrounded became a common pattern when group members felt threatened. In this process signifiers (Dalal, 1997) or social identity markers (Kennard, 2000) were used to define belonging with many assumptions about the beliefs, values and attitudes of others being made. This resulted in tribal formations (De Maré et al., 1991) that created alienation between opposing subgroups and ignored the subtle differences within groups.

Although the group tried to avoid the sensitive issues of 'politics and racism' by diverting a discussion as soon as tension was felt, painful feelings often emerged without 
warning and caused disruptive exchanges to occur repeatedly in this early phase. The new 'struggle' in South Africa, reflected in the group, seemed to be to find a way to talk to one another as equals who shared a history and had many commonalities, as this had not been historically possible.

\section{Reporting on the reshaping of social identity in the interviews and the first focus}

group

$C$ discussed in an interview that she had construed $B$ 's behaviour as reflecting a wide-spread, gendered, authoritarian attitude from men which she experienced daily in her own personal and work life. She became much quieter in the group after this incident as she was so afraid that as a second language English speaker she might use a 'wrong word' again, which could cause 'insanity' to erupt in the group. She felt extremely ambivalent about her social identity as an Afrikaner, as she felt this positioned her to be seen as 'an oppressor' or 'a racist' as had occurred in the incident reported. She felt acutely that there was 'no room' for her to explore her Afrikaans identity in the group or her family's story of pain and suffering during the South African War (1899 -1902). In her words the group at that time 'allowed only one story' to be told.

Another older, white group member, $M$, who had grown up under apartheid, felt her identity as a white person was under threat when these racialised interactions occurred and she defended herself with reactive, aggressive comments. She revealed in an interview how unfair she thought it was that assumptions were made that she was privileged and had not suffered hardships in her life because she was white. These assumptions prevented her from being able to share her experiences honestly. She experienced painful feelings of exclusion despite her four-year membership of the group.

An older, black group member, a resident of the local township, was silent in the 
group throughout the year. What emerged in an interview was that she had grown up under apartheid and had internalised the social stigma of being a black person. She had learnt from her family the need to suffer in silence as their community had no public voice and active protest was dangerous. The white median group members, concentrated in the senior year group, who spoke with authority and a sense of entitlement, made her feel that she had nothing to offer and increased her fear of being shamed for her inadequacies. She saw the mainly white staff group as unhelpful, uncaring and insensitive to her needs. She felt angry and despairing as she had hoped to attain the learning that had been denied her under apartheid, but what she experienced was a replication of her past. She managed to remain in the group, attentive yet silent.

\section{The first focus group}

$A$ discussed in a focus group how she had felt that she was stereotyped as a 'stupid black person' who did 'strange cultural things' when she had stood up in response to $B$ 's request as described above. She pointed out that she had stood because he had made the request politely using the respectful term 'mama' so she had not experienced his request as a command. She felt that 'the white group members', embodied in $C$, seemed to believe that black people could not think for themselves but needed 'to be helped' by whites, an attitude she experienced as patronising.

In the same focus group, some black members said that they saw the white members as needing to be able to say 'this is how [all] blacks think'. They objected to this stereotyping but felt they could not defend themselves because, as $D$ said, historically black people had always needed to be careful around whites.

A small group of black women, who were frequently absent from the median group, explained how they felt 'scrutinised and studied' or 'put under a microscope' in the 
median group. These women had been outraged by $C$ 's comments. This subgroup felt the median group should avoid any mention of cultural difference, as to notice such a difference might 'offend others'. They saw such comments as a 'mistake' as they were 'disrespectful and racist' and they believed such remarks were to be equated with the discriminatory practices of apartheid. They believed that the group should accept that 'we are all the same'.

In the median group, this group of women heatedly challenged any discussions to do with interracial or intercultural variations within the group. The paradox contained in this position was that this subgroup's sensitivity to being discriminated against meant that they treated unfairly the right of others to express their different social identities and positions.

Other group members also missed median group sessions. $Q$ used the term 'refugees' to describe her fellow group members who 'fled' from the median group experience, saying that 'they are terrified...fleeing from feelings'. These members confirmed in the first focus group that it was true that they fled from feelings and stayed away to protect themselves. $O$ and $U$ both said: 'We like to hate in that group'. These group members were afraid of their hatred and anger towards others who were of a different race, ethnic background, language or political affiliation from themselves. In addition, they did not believe that they could trust the group or the leadership to contain these overwhelming feelings.

These thoughts, voiced and elaborated in the marginal spaces of the interviews or the first focus group, were carried back to the median group and widened and deepened the shared understanding regarding the absentees from the group. It seems that it was the unexpressed anger and despair resulting from social trauma, held in the absent group members, and also in those present but silent, that found expression in the frequent 
disruptions and enactments.

\section{Establishing the relational matrix: the early phase}

Despite the staff team's emphasis on lateralisation (De Maré et al., 1991) the differences resulting from race, culture, class, gender, economic status and education were not explored in the early phase of the group. The tension that was felt was defended against by the extensive use of projective and introjective processes to locate denied feelings in groups seen as 'other'. The group was often passive, with members withdrawing into silence and being extremely cautious about speaking. $T$ said that 'by keeping silent you won't hurt the other or be attacked'. These constraints on thinking limited the possibility of dialogue and a healthy recognition of both we-ness and otherness.

Those group members who retained the ability to think and made tentative attempts to voice their difficulties were ignored or received with hostility. This prevented their thoughts being made accessible for discussion and translation (Foulkes, 1964) within the group matrix. The various defensive strategies prevented the original experience from being processed and internalised in a symbolic form, which would allow mourning to proceed (Hopper, 2011, 2012).

From repeated enactments it became clearer that the social history of the country, mirrored in the group, suggested that violent reprisals could result from conflict between opposing groups. The members had realised that strong feelings could emerge suddenly and without warning in the median group in response to deeply buried feelings triggered by 'a wrong word' or 'making a blunder' which was particularly likely when a second language was being used. Consequently, 'attacks that could not be mended' as $C$ phrased it, were feared. Additionally some group members did not believe that they could be safely dependant 
on the group or the staff team as their experience had been of oppressive leaders who used violence to maintain power.

\section{The relational matrix: the later stage}

Despite the tensions and difficulties, as the year evolved, more members gradually participated, thus strengthening the group matrix. The growth in social exchanges that some members achieved was possible because the group-as-a-whole could sustain the work despite accusations, blame, envy and hostility being expressed. A friendlier atmosphere was evident overall as is evident in Vignette 2 which follows. The group members were more able to acknowledge the concerns and fears of others as valid, even when they did not share those feelings.

As mentioned previously, there were many absentees at each session of the median group. Two of the members absent in Block VI (the block in which Vignette 2 took place), had left the group when they became unemployed and another group member became terminally ill. Members were frequently away when they attended funerals which take place on Saturdays in many communities. This ongoing reality of social trauma, both in the past and in the day-to-day lives of the participants, was able to be acknowledged by the group members as affecting their fellow members' ability to attend. This shift in stance from the judgemental attitudes that characterised so many interactions during the beginning phase, is one indicator of the social learning that had taken place.

\section{Vignette 2.}

In the first session of Block VI, the final block for the year, the session began with members sharing their sadness, anger and despair at the tragic death, at the local clinic, of a white, intern psychologist from the host organisation. $E$ said: 'It shuts down all the 
progress. All the good work gets shot down and forgotten'. An older, black female, $I$, supported this saying: 'She gave her life to help us [black people]' but added that the race aspect was not being talked about honestly in the press as young blacks were also gunned down. $M$, an older white female, reported that she had heard that a second person, a black health worker, had been shot at the same clinic on the same day, but that that event had not even been mentioned in the press. She said: 'That's the race issue and the cost of it.'

A black woman, $D$, commented that it was difficult to process endings and that the sadness of South African society was reflected in the sadness and loss in the group. Some people commented that this could be the reason for people staying away from the group and the presence of the eight empty chairs that day: it was just too difficult to work through these disturbing issues. Discussion followed regarding how the group missed the unique contributions of different members if they were absent.

A black, male group member shared that when he heard about the young woman's death he was reminded about a murder he had witnessed some years before. Concern was expressed for him and others who were carrying trauma and grief. $M$ tearfully said: 'We can talk about heartbreak but not anger. How do we protect ourselves from hatred and despair?' $N$, an older white female said: 'I am bewildered. I can't talk about it. It is such a trauma. It feels like a slow war. All the hopes we had in 1994 - what has happened? It is overwhelming.'

\section{Discussion of vignette 2}

The group in this vignette was able to support the young man who shared his memory of a trauma and they were able to recognise that he was giving voice to a shared pain. This seems to indicate that the group had learned how interconnected they were as members of a 
society with a shared history. Also significant is the fact that the voices of all the members have become valued and were 'missed' when absent.

Although regressive features were often apparent, for example the group sinking into hopelessness, despair and passivity, which transpired later in that session, on the whole the group was more able to contain this and recover their capacity to think again. Guilt and sadness for historical violations in the past began to be expressed. Mature hope (Hopper, 2003b) was also voiced by some members and sustained the work.

\section{Reshaping social identity: the interviews and focus groups}

In interviews and the second focus group, the group members described a process of attuning their social identities as they became more conscious of their similarities to, and differences from, others. They became aware of the social identity markers (Kennard, 2000) that they used when interacting with others and that often resulted in the use of stereotypes and unconscious assumptions. They began to notice that what is 'real' or the 'truth' to one person may not be so to another, and what matters to one person might not be important to another. Hearing 'the human element' was part of the process, as they were faced with a real, struggling person rather than a stereotype. $A$ said: 'After hearing their stories I understood why they felt the way they did.' The multiple opportunities for mirroring were an important aspect of the process.

Members became aware that their comments could not be tailored to be acceptable or understood by every individual present, but that they could try to express themselves sensitively. $F$ said that: 'It is now easier for me to say what I want to and I feel I can express my views and be sensitive to how and when I say it. I try to put things in a respectful way. I have also become more tolerant of myself if I get it wrong.' 
The group members became less reactive to events in the group as they no longer heard comments as an attack on their racial, cultural or political group. $S$ said he 'learnt patience' so that he was able to 'sit with not liking people or not being understood'. $V$ said: 'Initially I would leave feeling angry and want to discuss it outside. I have learnt to live with it, listening to others. I have learnt to accept what is being said.'

$M$ described having realised why a group member needed to identify strongly with a political figure that she herself did not respect. This insight helped her relationship with the group member, but in addition, it transferred to other similar situations outside the group when she might have been dismissive of a person holding these views. She also described her growing awareness of the effect her developmental traumas had had on her need to belong and to feel socially accepted in the group. She realised that she became hostile and defensive when she felt threatened.

Resulting from the median group experience $C$, the Afrikaans speaker, mentioned becoming interested, for the first time, in her family's history and social positioning as she became more aware of the socio-political history of the country. 'The group helped me to find and articulate my social identity' she said. As mentioned previously she became quieter in the group and often was absent, but her social learning continued in different contexts. Like other group members she began to realise she did not have to define herself socially according to an ascribed label, such as an 'oppressor' as other identities could be embraced that were meaningful to her. Her growing social awareness had an impact on her professional and personal life even though she did not share much of herself in the median group.

$H$, a local township resident living in a situation of unrest, poverty and xenophobia, explained how exploring his enraged response to members of the median group with different ethnic and political allegiances, helped him to manage his feelings of frustration and rage in his turbulent social world. He came to understand that he felt marginalised in the group and 
in his township, where the political and socio-economic changes, including corruption and nepotism, had destroyed the hope he had felt in 1994. Making connections and establishing links between inner and outer experiences, between feeling and behaviour, between self, family and the social world and its history, were all apparent in him.

Racial and intercultural relationships were specifically mentioned as an area of growth. The median group offered members a space for thinking critically about their multiple identities and opportunities to become aware of how, why and where they erected psychological barriers that kept fellow group members defined as other when in fact many commonalities existed between them. One such opportunity, particularly relevant in the South African context, was the opportunity to become aware of the extent to which race is used as a negative cultural reservoir (Volkan, 2004) for the projection and externalisation of unacceptable aspects of the self. $O$ for example said: 'It has helped me be less anxious about the race thing. Before I did not know how to raise it without being politically incorrect and yet to be authentic. It feels easier now' and $P$ said: 'It's encouraging - it is possible to get beyond barriers and gives hope in other situations'.

The group members acknowledged that understanding as well as the ability 'to do things differently' in relationships was necessary. $M$ said: 'It is a difficult task. It means engaging with each new person again and again and being prepared to go on when you don't want to do it. You have to keep doing it and doing it with different people.' The median group, which provided many encounters that replicated real life situations, enabled decisions based upon new learning to be taken.

\section{Reshaping of the researcher's social awareness}

The researcher's social awareness underwent a transformation in the emotionally charged, intersubjective context of this research. She was made painfully aware of the 
constraints that her racial, cultural and professional status placed on her as the researcher. The power dynamics inherent in the relationship between her and the group members initially blocked the development of a research partnership characterised by the equality that she desired. She learned the power of the assumptions that are made when social identity markers and the configurations of power associated with them were used as a source of information. She learned that being respectful and ethical was not enough to earn the trust of the group members. Trust had to be earned slowly by remaining connected and in communication despite feeling misunderstood, being rebuffed and feeling she was disliked, and even momentarily hated. As she became more attuned to the group members and empathic towards their difficulties, a research partnership that enriched both herself and the group members, became possible.

\section{Reflection on working in an interracial, transitional setting}

Some thoughts on what was learned through these experiences are offered in this section.

- The multi-method research design provided a unique opportunity for the researcher to explore the social matrix of the median group. In addition the interviews came to be valued by the group members as a space for reflection, for the integration of their experiences and for an exploration of the meaning attached to events in the group. In the interviews towards the end of the year, group members reported that they had become more conscious of the social, cultural and political influences on their internal conflicts and relational difficulties.

- The focus groups emerged as an additional space for connection and social learning. This indicates that the method may be useful in similar contexts where participants may be reserved about their use of language, lacking in confidence to express 
their thoughts or sensitive to 'being studied' or objectified. In particular these groups were effective in eliciting unshared material, such as divergent and strongly held positions. Marginalised members found their voices which is a recognised benefit of focus groups (Palmer, Larkin, De Visser, \& Fadden, 2010). Two women, for example, who had declined to be interviewed, attended both the focus groups and were highly motivated to be heard. The voices of the powerful white Training group were, on the whole, much more restrained in the focus groups, as they seemed to enjoy listening to the other members talking more freely.

The group members referred to the second focus group, held after the end of the course, as 'a debriefing' and as 'giving closure', suggesting that focus groups could be a novel way to help struggling participants, such as the group members who were described as often missing the group. In that focus group they received support and integrated their experiences of the median group. Such an addition might have potential as a complementary component on a course. Hopper and Garland (2003) and Ahlin (2010) referring to large groups, suggest that preparation may be necessary to assist newcomers and this would seem to be particularly true of groups with an interracial composition.

- The small groups emerged as very significant for the group members, particularly in the early phase when the group was characterised by fragmentation and a lack of cohesion. In the South African context it seems that small groups are needed to complement the work of the median group, as so many group members are carrying developmental and social traumas. Many group members said that they would not have been able to attend the median group except for the support they received in their small experiential groups. However, even the small groups did not provide sufficient containment for the group members who often absented themselves.

- Since this research was conducted, the composition of the median 
group has become less diverse, as a focus on training has narrowed the intake of participants. Financial constraints have also limited the number of subsidised places that can be offered. This has resulted in a group with less opportunities for the social reshaping that occurred in the research year, although the experience is still described as 'a profound learning experience' as a member recently reported. In the future, for the transformative nature of this type of work to be sustained, 'social sponsorship' of group members who would benefit from the course whilst contributing to the diversity, may be required.

- During the research, the median group members commented that the various language groups were visible at the tea and lunch breaks and offered their members a sense of belonging and containment. However, these languages were only heard in the median group at times of tension when group members spoke in dyads and subgroups. This was despite the fact that only seven group members were in fact first language English speakers. Being able to speak what a group member called 'high English,' is seen as a signifier of educational level and enhanced social class and carries with it many different aspirational dimensions, most of them linked to social identity. Since this research was conducted home languages are used more frequently in the median group as the staff team has worked hard to facilitate this by supporting their use in the different course spaces.

- This richly diverse median group was embedded in a course structure in which the value of the participation by each member was conveyed. This created a unique learning community, as the group members, historically separated, had much to learn from one another. The median group functioned within this structure as an alternative discourse community in which the whole group faced an unknown and confusing situation that provided the opportunity for different meaning-making frameworks to be developed. One aspect of this meaning-making was the role of the 'other' in their lives. 'Knowing something with others' (De Maré, 1985: 80) was an active process of participation that included not 
understanding, being vulnerable, 'making a social blunder', recovering a sense of being valued and making efforts to be reconciled to others. As the group members clarified their social identities they were more able to hold onto their own distinctiveness, whilst acknowledging both the uniqueness of others and their shared humanity.

This learning was made possible by the staff team maintaining a specific stance as part of their commitment to working with social diversity. In the reflective staff meetings held after each median group, the themes emerging from the different aspects of the programme, such as the small groups, as well as material from the median group, were carefully considered. The unconscious constraints on thinking and feeling, and the topics and discourses that emerged, as well as those that were avoided, were seen as manifestations of the social unconscious, and were often a part of these deliberations. Tensions and difficulties emerging relationally in the racially and culturally mixed staff team were other aspects that were discussed. These various strands of meaning were gathered together into a comprehensive understanding to guide the work in subsequent median group sessions.

Staff recruitment that reflects the diversity of South Africa has been difficult but the future seems hopeful as graduates from the $\mathrm{WwG}$ course are now beginning to undertake staff roles.

\section{Concluding thoughts}

The median group offered a context for the exploration of interracial and intercultural relationships and for the elaboration of trauma in the South African context. The group showed a progression that reflected the sequence, used by De Maré et al. (1991) as the subtitle of the book Koinonia, as being from hate through dialogue to culture in the group. An overall transition from mistrust and distance to a more dialogical stance characterised by greater tolerance and friendliness was observed. By being-in-relation to others in the group, 
the group members, the researcher and the staff team were able to reshape their social

identities and undergo a social learning experience that encouraged their development as citizens in a transitional social context.

Notes

i. This 'report' covers an extended period during which many social events happened that provided directional encounters in the group. Only a specific selection is offered here.

ii. The research discussed formed part of the requirements for a $\mathrm{PhD}$ in the Department of Psychology of the Faculty of Humanities at the University of Pretoria, South Africa.

iii. Consent was initially obtained from the Ethics Committee of the host organisation. The staff team of the WwG Course also gave their consent. Formal approval was then obtained from the PostGraduate Research and Ethics Committee of Faculty of Humanities at the University of Pretoria. All the potential group members were informed of the research component of the course. Their consent to the observation of the median group and to the transcripts that would be compiled of the median group, the interviews and the focus groups was obtained.

iv. Further details regarding the process used to obtain informed consent and the steps taken to ensure the procedures were understood by the group members are contained in the unpublished thesis on which this paper is based. This may be obtained from the authors on request.

V.

\section{Acknowledgements}

We acknowledge the contribution of the course members, the staff team and the support staff at Ububele, Johannesburg, who have all contributed to this transformational experience over many years.

\section{References}

Ahlin, G. (2010) 'Notions about the Possibilities in Large Groups'. Group Analysis, 43(3): 253-67.

Brown, D. (2001) 'A Contribution to the Understanding of the Social Unconscious'. Group Analysis, 34(1): 2938.

Becker, L., Beech, T., \& Spiro, M. (2013) 'Small and Large Groups as Containers for Transformation in a Group Analytic Training Programme: Cape Town, South Africa'. Group Analysis, 46(3): 286-298.

Behr, H., \& Hearst, L. (2005) Group-Analytic Psychotherapy: A Meeting of Minds. London: Whurr.

Berman, A. (2014) 'Post-Traumatic Victimhood and Group Analytic Therapy: Intersubjectivity, Empathic Witnessing and Otherness'. Group Analysis, 47(3): 245-55.

Dalal, F. (1997) 'A Transcultural Perspective on Psychodynamic Psychotherapy: Addressing Internal and External Realities'. Group Analysis, 30(2): 203-15. 
Dalal, F. (2001) 'The Social Unconscious: A Post-Foulkesian Perspective’. Group Analysis, 34(4): 539-55.

De Maré, P.B. (1985) 'Large Group Perspectives’. Group Analysis, 18(2): 79-92.

De Maré, P.B. (1990) ‘The Development of the Median Group’. Group Analysis, 23(2): 113-27.

De Maré, P.B. (1994) 'The Median Group and the Psyche', in D. Brown \& L. Zinkin (eds.) The Psyche and the Social World: Developments in Group-Analytic Theory, pp. 202-10. London: Routledge.

De Maré, P.B. (2002) ‘The Millennium and the Median Group’. Group Analysis, 35(2): 195-208.

De Maré, P.B., Piper, R., \& Thompson, S. (1991) Koinonia: From Hate, through Dialogue to Culture in the Large Group. London: Karnac.

De Mendelssohn, F. (2000) 'The Aesthetics of the Political in Group Analytic Process - The Wider Scope of Group Analysis'. Group Analysis, 33(4): 438-58.

Durrheim, K., Mtose, X., \& Brown, L. (2011) Race Trouble: Race, Identity and Inequality in Post-Apartheid South Africa. Pietermaritzburg: University of KwaZulu-Natal Press.

Foulkes, S.H. (1964) Therapeutic Group Analysis. New York: International Universities Press.

Foulkes, S.H. (1990) 'Notes on the Concept of Resonance (1977)', in E. Foulkes (ed.) Selected Papers of S.H. Foulkes: Psychoanalysis and Group Analysis, pp. 297-306. London: Karnac.

Hopper, E. (2001) ‘The Social Unconscious: Theoretical Considerations’. Group Analysis, 34(1): 9-27.

Hopper, E. (2003a) 'On the Nature of Hope in Psychoanalysis and Group Analysis', in E. Hopper (ed.) The Social Unconscious: Selected Papers, pp. 189-204. International Library of Group Analysis 22. London: Jessica Kingsley.

Hopper, E. (2003b) 'The Fourth Basic Assumption: Incohesion: Aggregation/Massification or (ba) I:A/M', in E. Hopper Traumatic Experience in the Unconscious Life of Groups. The Fourth Basic Assumption: Incohesion: Aggregation/Massification or (ba) I:A/M, pp. 66-90. International Library of Group Analysis 23. London: Jessica Kingsley.

Hopper, E. (2011) 'Forward', in E. Hopper, \& H. Weinberg (eds.) The Social Unconscious in Persons, Groups and Societies, Vol. 1, pp. xvii-xxii. London: Karnac.

Hopper, E. (2012) 'Introduction', in E. Hopper (ed.) Trauma and Organizations, pp. xxxi-li. London: Karnac.

Hopper, E., \& Garland, C. (2003) 'Overview of the Survivor Syndrome Workshop (1979)', in E. Hopper (ed.) The Social Unconscious, pp. 95-102. London: Jessica Kingsley. 
Island, T.K. (2003) 'The Large Group and Leadership Challenges in a Group Analytic Training Community', in S. Schneider \& H. Weinberg (eds.) The Large Group Re-Visited. The Herd, Primal Horde, Crowds and Masses, pp. 201-13. London: Jessica Kingsley.

Kennard, D. (2000) 'Some Differences Between the Small Therapeutic Group and the Median Group: Commentary on Special Issue on Dr Patrick de Maré (Group Analysis, March 2000)'. Group Analysis, 33(4): 575-78.

Lorentzen, S. (2004) 'Comparing Large Group Processes within Group Analytic Training Programs in Norway and the Baltics'. Group, 28(3): 211-26.

Mojovic, B.M. (2007) 'The Impact of the Post-Totalitarian Social Context on the Group Matrix'. Group Analysis, 40(3): 394-403.

Palmer, M., Larkin, M., De Visser, R., \& Fadden, G. (2010) 'Developing an Interpretative Phenomenological Approach to Focus Group Data'. Qualitative Research in Psychology, 7(2): 99-121.

Rogers, C. (2013) 'Engaging with the Median Group’. Group Analysis, 46(2): 183-95.

Rohr, E. (2013) 'From Conflict to Recognition: Cultural Transformation through Group Supervision in Guatemala'. Group Analysis, 46(2): 272-85.

Tindall, C. (2006) 'Issues of Evaluation’, in P. Banister, E. Burman, I. Parker, M. Taylor, \& C. Tindall (eds.) Qualitative Methods in Psychology. A Research Guide, pp.142-59. New York: Open University.

Volkan, V.D. (2001) 'Transgenerational Transmissions and Chosen Traumas: An Aspect of Large Group Identity’. Group Analysis, 34(1): 79-97.

Volkan, V.D. (2004) Blind Trust: Large Groups and Their Leaders in Times of Crisis and Terror. Charlottesville, VA: Pitchstone.

Von Sommaruga Howard, T. (2012) 'To Stand Sitting! Bi-Cultural Dilemmas in a Large Group in Aotearoa, New Zealand'. Group Analysis, 45(2): 219-43.

Weinberg, H. (2007) 'What Is the Social Unconscious?'. Group Analysis, 40(3): 308-22.

Hilary Vice is an educational psychologist and group analyst who has worked in various communities in and around Johannesburg as well as having a private psychology practice. She has been a staff member in this community training programme from its inception.

Address: 6 Meyer Street, Oaklands, 2192, South Africa.

Email: hilary.vice@iafrica.com 
Assie Gildenhuys is a clinical psychologist and senior lecturer in the Department of Psychology at the University of Pretoria, South Africa. He has been involved in mental health projects and with the training of clinical psychologists in community and mental health settings. He has been a staff member in this community training programme from its inception. He is a board member of the International Association of Group Psychotherapy and Group Process.

Address: Department of Psychology, University of Pretoria, Pretoria, 0002, South Africa.

Email: assie.gildenhuys@up.ac.za 